\title{
Dentistry vs Severe Acute Respiratory Syndrome Coronavirus 2: How to face this enemy
}

\author{
Odontologia vs Sindrome Respiratória Aguda Severa \\ Coronavirus 2: Como enfrentar o inimigo
}

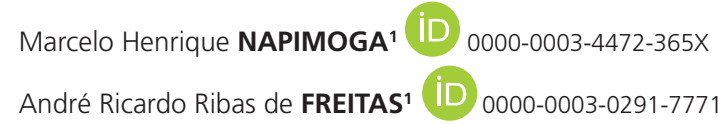

\section{ABSTRACT}

Since the beginning of the SARS-CoV-2 pandemic, numerous restrictive measures have been taken by the governments of different countries. Recently, due to the high possibility of transmission in dental offices, there was a recommendation by the American, European and Brazilian governments to request the closing of the offices. In this commentary, we will give an overview of the reasons and perspectives of this scenario.

Indexing terms: SARS-CoV-2. Covid-19. Coronavirus. Dentistry. Dental office. Odontology.

A novel coronavirus, severe acute respiratory syndrome coronavirus 2 (SARS-CoV-2), associated with severe respiratory illness emerged in Wuhan, China, in late 2019 [1].

Several dental associations worldwide recommended or even obligate dentists postpone elective procedures on March 16th 2020. By a public health emergency perspective, when social distancing has been ordered at all levels of government, continuing practicing in the dental office even with personal protective equipment, would be irresponsible. Among the reasons is that the uncertain about the virus incubation time which has been estimated to vary from 5 to 6 days, with a range of up to 14 days [2] and even the reappearance in recovered patients [3]. Therefore, some asymptomatic or subclinical infected patients characterized by mild symptoms, but both are contagious, which leads to the possibility of unintentional viral spread within dental offices.

Significant environmental contamination by patients with SARS-CoV-2 through respiratory droplets and fecal shedding suggests the environment as a potential medium of transmission and supports the need for strict adherence to environmental and hand hygiene [4]. The health care workers ( $\mathrm{HCWs}$ ) were recognized as high-risk group to acquire this infection. In a case series of 138 patients treated in a Wuhan hospital, 40 patients (29\% of cases) were HCWs. When the viruses arrived to Singapore from a total of 47 cases have been confirmed among the first 25 locally transmitted cases, 17 cases (68\%) were

$\boldsymbol{\nabla v}$

${ }^{1}$ Faculdade São Leopoldo Mandic. Instituto São Leopoldo Mandic. R. José Rocha Junqueira, 13 - Swift Cep 130455-755, Campinas/SP, Brazil. Correpondence to: MH NAPIMOGA. E-mail: marcelo.napimoga@sImandic.edu.br

$\boldsymbol{v} \boldsymbol{v}$

How to cite this article

Napimoga MH, Freitas ARR, Dentistry vs Severe Acute Respiratory Syndrome Coronavirus 2. How to face this enemy. RGO, Rev Gaúch Odontol. 2020;68:e20200011. http://dx.doi.org/10.1590/1981-863720200001120200034 
probably related to occupational exposure [5]. Thus, the dental office may be considered an important place to spread the SARS-CoV-2 and dentists are among the HCW to acquire the new pneumonia. In addition to the infected patient's cough and breathing, dental devices such as high-speed dental hand piece produces a large amount of aerosol and droplets mixed with the saliva or even blood is formed. Those particles of droplets and aerosols are small enough to stay airborne for an extended period before they settle on environmental surfaces or enter the respiratory tract. Besides, human coronaviruses like SARS$\mathrm{CoV}$ (severe acute respiratory syndrome coronavirus) and MERS-CoV (Middle East respiratory syndrome coronavirus) can remain infectious on inanimate surfaces for up to 9 days. Surface disinfection with $0.1 \%$ sodium hypochlorite or $70 \%$ ethanol significantly reduces coronavirus infectivity on surfaces within 1 min exposure time, which is expected a similar effect against the SARS-CoV-2 [6].

Thus, after this worldwide effort to promote social distancing and thus community mitigation, the practical strategies to block virus transmission and for preventing the transmission of SARS-CoV-2 during dental diagnosis and treatment, include full patient evaluation, rigorous hand hygiene, personal protective measures for the dental professionals, mouthrinse before dental procedures, rubber dam isolation, anti-retraction hand piece, disinfection of the clinic settings, and ear a surgical mask and eye protection with solid side shields or a face shield to protect mucous membranes of the eyes, nose, and mouth during procedures correct management of medical waste [7].

Much of the actual uncertainty relates to the nature of a novel pathogen, especially a potentially lethal coronavirus with unique person-to-person transmission. Nobody has previous experience with it, immunologically or otherwise, and there is still much to learn about its wildlife origins and disease dynamics. Researchers are running to find some possible drugs to help patients recover, as well as possible vaccines and even rapid tests to identify infected patients [8]. Immunological evidences on the recruitment of immune cell populations (antibodysecreting cells, follicular helper T cells and activated CD4+ and CD8+ T cells), together with IgM and IgG SARS-CoV2-binding antibodies, in the patient's blood before the resolution of symptoms, shows that our immune system may control this virus [9]. We will win!

\section{REFERENCES}

1. Munster VJ, Koopmans M, van Doremalen N, van Riel D, de Wit E. A Novel Coronavirus Emerging in China - Key Questions for Impact Assessment. N Engl J Med. 2020;382(8):692-694. doi: 10.1056/NEJMp2000929.

2. Huang $C$, Wang $Y$, Li $X$, Ren $L$, Zhao J, Hu Y, et al. Clinical features of patients infected with 2019 novel coronavirus in Wuhan, China. Lancet. 2020;395:497-506.

3. Lan L, Xu D, Ye G, Xia C, Wang S, Li Y, Xu H. Positive RT-PCR Test Results in Patients Recovered From COVID-19. JAMA. 2020 Feb 27. doi: 10.1001/jama.2020.2783.

4. Desai AN, Patel P. Stopping the Spread of COVID-19. JAMA. 2020 Mar 20. doi: 10.1001/jama.2020.4269.

5. Koh D. Occupational risks for COVID-19 infection. Occup Med (Lond). 2020 Mar 12;70(1):3-5. doi: 10.1093/occmed/ kqaa036

6. Kampf G, Todt D, Pfaender S, Steinmann E. Persistence of coronaviruses on inanimate surfaces and their inactivation with biocidal agents. J Hosp Infect. 2020 Mar;104(3):246-251.

7. Peng $X, X u X, L i Y$, Cheng L, Zhou X, Ren B. Transmission routes of 2019-nCoV and controls in dental practice. Int J Oral Sci. 2020 Mar 3;12(1):9. doi: 10.1038/s41368-020-0075-9.

8. Sabino-Silva R, Jardim ACG, Siqueira WL. Coronavirus COVID-19 impacts to dentistry and potential salivary diagnosis. Clin Oral Investig. 2020 Feb 20. doi: 10.1007/ s00784-020-03248-x.

9. Thevarajan I, Nguyen THO, Koutsakos M, Druce J, Caly L, van de Sandt CE, Jia X, Nicholson S, Catton M, Cowie B, Tong SYC, Lewin SR, Kedzierska K. Breadth of concomitant immune responses prior to patient recovery: a case report of non-severe COVID-19. Nat Med, 2020. doi: 10.1038/s41591-0 20-0819-2. 